\title{
Nasal Gel Loaded with Amphotericin Nanotransferosomes as Antifungal Treatment for Fungal Sinusitis
}

\author{
Khaled M. Hosny ${ }^{1,2, *}$ and Nabil A. Alhakamy ${ }^{1,2} \mathbb{D}$ \\ 1 Department of Pharmaceutics, Faculty of Pharmacy, King Abdulaziz University, Jeddah 21589, Saudi Arabia; \\ nalhakamy@kau.edu.sa \\ 2 Center of Excellence for Drug Research and Pharmaceutical Industries, King Abdulaziz University, \\ Jeddah 21589, Saudi Arabia \\ * Correspondence: kmhomar@kau.edu.sa; Tel.: +966-592722634
}

check for

updates

Citation: Hosny, K.M.; Alhakamy, N.A. Nasal Gel Loaded with Amphotericin Nanotransferosomes as Antifungal Treatment for Fungal Sinusitis. Pharmaceutics 2021, 13, 35. https://doi.org/10.3390/pharmaceutics 13010035

Received: 28 November 2020 Accepted: 21 December 2020 Published: 28 December 2020

Publisher's Note: MDPI stays neutral with regard to jurisdictional claims in published maps and institutional affiliations.

Copyright: (c) 2020 by the authors. Licensee MDPI, Basel, Switzerland. This article is an open access article distributed under the terms and conditions of the Creative Commons Attribution (CC BY) license (https:// creativecommons.org/licenses/by/ $4.0 /)$.

\begin{abstract}
On the basis of fungal involvement, rhinosinusitis is categorized into allergic, mycetoma, chronic, and acute invasive types. The aim of the current study was to evaluate the efficacy of an amphotericin gel in situ loaded with nanotransferosomes against Aspergillus flavus, which causes allergic rhinosinusitis. A Box-Behnken design was utilized to study the interaction among the nanotransferosomes and optimize independent variables in formulating them, in order to match the prerequisites of selected responses. The optimal formulation was determined to be $300 \mathrm{mg} / \mathrm{mL}$ soybean lecithin, $200 \mathrm{mg} / \mathrm{mL}$ amphotericin B (AMP), and $150 \mathrm{mg} / \mathrm{mL}$ clove oil, resulting in a particle size of $155.09 \mathrm{~nm}, 84.30 \%$ entrapment efficacy (EE), inhibition zone of $16.0 \mathrm{~mm}$, and $0.1197 \mathrm{mmol}$ serum creatinine. The optimized batch was further prepared into an in situ gel and evaluated for various parameters. The optimized formulation released 79.25\% AMP and enhanced permeation through the nasal membrane, while the other formulations did not achieve complete absorption. According to in vivo tests using rabbits as animal models, the optimized AMP-nanotransferosomal formulations (NT) in in situ gel result in a non-significant difference among the various kidney function parameters. In conclusion, nasal in situ gel loaded with AMP-clove oil nanotreansfersomes can act as a promising novel carrier that enhances antifungal activity and decreases AMP nephrotoxicity.
\end{abstract}

Keywords: Amphotericin B; Box-Behnken Design; clove oil; Aspergillus flavus; nanotransferosomes

\section{Introduction}

In recent years, an escalating number of paranasal sinus fungal infections has been reported. The majority are attributed to the Aspergillus species [1,2], while others include other fungal pathogens of the Zygomycetous and Dematiaceous genera [3]. On the basis of pathological conditions, fungal rhinosinusitis is characterized into non-invasive (allergic and mycetoma) and invasive (chronic and acute) types [4,5].

Amphotericin B (AMP) is a broad spectrum antibiotic that has been widely used to treat fungal infections (as a first-line management) and various leishmaniasis (as a second line management) [6,7]. Since its discovery in the 1960s, various dosages and formulations have been researched in order to lessen the toxicity and augment the therapeutic efficiency. In particular, several nanoparticle formulations, including polymeric nanoparticles [8,9], nanocapsule [10], liposome [11], solid lipid nanoparticle [12,13] and micelles [14], have been developed to achieve the foresaid goals. Several commercial forms of AMP, such as micellar dispersion, liposomes, lipid-base formulation, have been also been intensively researched. However, these systems suffer from dose-dependent toxicity [15], shortage of support for long-standing benefits [16,17], towering expenditure, and contradictory results. Furthermore, AMP possesses several intrinsic confines, such as propensity to degradation (oxidation and/or light induced), low water-solubility, hepatotoxicity, nephrotoxicity, in addition to anemia-related symptoms [18]. Thus, numerous investigations have been 
performed on several carriers for AMP as a protection mechanism from various degradation pathways and to reduce its inherent toxicity.

Eugenol, a chief active ingredient in clove oil, has proven analgesic, anti-inflammatory antibacterial, and local anesthetic effects. In addition, eugenol exhibits anti-inflammatory activity through a cyclooxygenase II inhibitor [COX-2 Inhibitor], as proposed in molecular studies by Hong et al. [19]. Also, Jadhav et al. suggested the anti-inflammatory activity and analgesic activity of eugenol through cycloxygenase-II enzyme and capsaicin receptor activity, respectively [20].

Other studies report that eugenol has antibacterial activity against several Gram positive and negative bacteria and can be used in a topical application with prilocaine or lidocaine owing to its anti-nociceptive action. Eugenol at a concentration of $5-18 \%$ is safe for topical application; it may cause local irritation when present in concentration more than $18 \%$ [21].

Drug delivery through the skin for systemic benefits has been realized by a wide range of transdermal systems, but still faces several issues related to the permeation of active moieties. Therefore, various nano/vesicular systems have been shown to be a promising alternative to enhance permeation across the skin [22]. In this view, a new type of carrier system called "transferosome" has been introduced. Transferosomes are ultra-flexible lipid molecular aggregates consisting of an inner aqueous section bounded by lipid bilayer and, thus, are efficient in delivering both low and high molecular weight drugs. The lipid layer allows special customized properties, which are attributable to the occurrence of "edge activators" [23]. When applied under non-occlusive conditions, the flexibility of nano-transferosomes minimizes the risk of vesicle rupture and follows a natural water gradient pathway. Nano-transferosomes can penetrate through the stratum corneum via trans and inter cellular routes, and trans-pore hydrostatic pressure difference serves as the driving force for this transportation [24].

Response surface methodology (RSM) is the most accepted strategy for the development and optimization of several drug-delivery systems [25]. RSM involves the application of various experimental designs and polynomial relationships to map the responses over the experimental domain. Different types of design, such as D-Optimal, central composite, and Box-Behnken designs (BBD), are available for statistical optimization. For the current study, BBD was selected due to its independent, rotatable designs for treatment combinations, fewer experimental runs, and cost-effective technique in optimizing the formulation preparation [26].

The rationale for selecting the nano-transferosomes was to attain to enhance the solubility and attain optimal delivery of the selected AMP (low-soluble drug) following an invasive approach.

The impact of eugenol as edge activator and to enhance the anti-microbial activity of AMP was studied through RSM. The objective of the present work was to design and formulate an in situ gel loaded with the optimized formulation of nano-transferosomes using ellagic acid to improve the bioavailability and diminish the dose-related toxicities.

\section{Materials and Methods}

\subsection{Materials}

Amphotericin B was purchased from Sigma-Aldrich Co. (St Louis, MO, USA). Tween was acquired as a generous gift from Saudi Drugs and Medical Instruments Company (SPIMACO), in Qassim, Saudi Arabia. Clove oil was procured from Avanti Polar liquids (Alabaster, AL, USA). High-performance liquid chromatography (HPLC) grade solvents were collected form Merck (Germany). All other reagents and chemicals used were of analytical grade.

\subsection{Methods}

2.2.1. Preparation of Amphotericin B Nanotransferosomes (AMP-NT)

A conventional thin-layer evaporation technique was utilized to prepare AMP-loaded nanotransferosomal formulations (AMP-NT). The effect of the selected independent vari- 
ables on different responses was demonstrated by applying 3 factor, 3 level BBD. As per the projected experimental plan (Table 1), a total of 17 formulations were planned per the design. Specific amounts of soybean, AMP, and clove oil were added to a dried roundbottom flask containing the solvent mixture (methanol and chloroform at 2:1 $v / v$ ) and allowed to evaporate at $45^{\circ} \mathrm{C}$, at $60 \mathrm{rpm}$ under low pressure Heidolph rotavap ML/G3 (Heidolph Instruments GmbH\& CO., Schwabach, Germany) until a thin lipid layer formed on the inner walls of the flask. The final solvent residuals were removed under vacuum. Finally, the dried thin layer was reconstituted with PBS (phosphate buffer) with $\mathrm{pH}$ of 7.4 under continuous stirring for $60 \mathrm{~min}$. The vesicles formed were allowed to swell at room temperature for 2-3 h $[27,28]$. The multilamellar vesicles were sonicated by Digital Sonifier (St Louis, MO, USA) for 15-20 min to lessen the vesicles' size and subsequently stored at $4{ }^{\circ} \mathrm{C}$ until further study.

Table 1. Experimental plan for amphotericin B-loaded nanotransferosomal formulations (AMP-NT).

\begin{tabular}{|c|c|c|c|c|c|}
\hline \multirow{2}{*}{ Independent Variables } & \multicolumn{3}{|c|}{ Levels } & \multirow{2}{*}{ Dependent Variables } & \multirow{2}{*}{ Constraints } \\
\hline & -1 & 0 & +1 & & \\
\hline Soybean Lecithin $(\mathrm{mcg} / \mathrm{mL})-\mathrm{X}_{1}$ & 100 & 200 & 300 & Particle Size (nm) & Minimum \\
\hline Amphotericin B $(\mathrm{mcg} / \mathrm{mL})-\mathrm{X}_{2}$ & 100 & 200 & 300 & $\begin{array}{c}E E(\%) \\
\text { Inhibition Zone }\end{array}$ & $\begin{array}{l}\text { Maximum } \\
\text { Maximum }\end{array}$ \\
\hline Clove oil $(\mathrm{mcg} / \mathrm{mL})-X_{3}$ & 50 & 100 & 150 & Serum creatinine & Minimum \\
\hline
\end{tabular}

$E E \%$ : Entrapement Effeciency.

\subsubsection{Experimental Design}

BBD was performed using DESIGN EXPERT 12 (Stat-Ease Inc., Minneapolis MN, USA) to study the interaction effects. Furthermore, factor association between the variables was analyzed by response surface graphs. Soybean lecithin $(\mathrm{mcg} / \mathrm{mL})(\mathrm{X} 1)$, AMP $(\mathrm{mcg} / \mathrm{mL})$ $(\mathrm{X} 2)$, and clove oil $(\mathrm{mcg} / \mathrm{mL})(\mathrm{X} 3)$ were considered the independent variables, and the factorial levels for these factors were coded as -1 (low level), 0 (medium level), or +1 (high level) [23]. Particle size (PS-Y1), entrapment efficacy (EE-Y2), inhibition zone (Y3) and serum creatinine (Y4) were chosen as the responses to be evaluated. Analysis of variance (ANOVA) was requisite to ascertain the statistical rationale of generated equations [29,30]. All experimental results were concomitantly fitted to various models, and the best fitting models (main, interaction, or quadratic) were selected based on statistical parameters, including multiple correlation coefficient (R2), adjusted R2, and predicted R2. In general, the non-linear quadratic design matrix is defined as follows:

$$
Y_{i(\text { Quadratic })}=b_{0}+b_{1} X_{1}+b_{2} X_{2}+b_{3} X_{3}+b_{12} X_{1} X_{2}+b_{13} X_{1} X_{3}+b_{23} X_{2} X_{3}+b_{11} X_{1}^{2}+b_{22} X_{2}^{2}+b_{33} X_{3}^{2}
$$

\subsubsection{Characterization of AMP-NT}

AMP-NTs were characterized for vesicle size and zeta potential using (Malvern instruments, Malvern, UK) by a dynamic light scattering process [31]. Each formulation was measured three times $(n=3)$ to obtain averages [32].

\subsubsection{Entrapment Efficacy $(E E) \%$}

EE was generally expressed as a fraction of drug available in the prepared AMP-NT and was determined by an indirect technique. The prepared formulation was added to a Petri dish. Freeze-dried, then the required quantity of acetonitrile was added and mixed vigorously to the dried sample [27]. The resulting dispersion was then centrifuged for $1 \mathrm{~h}$ at 10,000 rpm. The supernatant liquid formed was collected and then washed again with acetonitrile. All of the washing contents and supernatant liquid were added together and dried using a water bath. Subsequently, a precise amount of methanol was added to the 
final dried extract, which was diluted and measured at an absorbance of $450 \mathrm{~nm}$. EE was estimated using the following formula:

$$
E E(\%)=\frac{\text { Ctotal }- \text { Cfree }}{\text { Ctotal }}
$$

where Ctotal is the theoretical concentration; and Cfree is the concentration of drug found in the supernatants.

\subsection{In Situ Gel Preparation}

In situ gel formulation of AMP was prepared by sprinkling Deacetylated gellan gum DCG (cationic induced in situ gel polymer) into $6 \mathrm{~mL}$ distilled water at high temperatures $\left(80 \pm 2{ }^{\circ} \mathrm{C}\right)$, then the solution was stirred continuously until the polymer dissolved. The dispersion formed was allowed to cool throughout the night $[33,34]$. Another $4 \mathrm{~mL}$ AMPNT was added to the above prepared solution and then mixed to produce the situ gel of AMP.

\subsection{Evaluation of AMP-NT In Situ Gels}

\subsubsection{Critical Ionic Concentration (CIC)}

The critical ionic concentration (CIC) for phase transition is an imperative parameter for in situ gels that are activated through ions. Initially, various quantities of artificial nasal fluid (NF) and $1 \mathrm{~mL}$ of $0.5 \%$ Deacetylated gellan gum solution were mixed together. Then, the resulting solution was inserted into bottles and placed in a water bath maintained at a temperature of $32{ }^{\circ} \mathrm{C}$. After $20 \mathrm{~s}$, the filled bottles were turned over. If the formulation contains the gel formation, then the content will adhere to the bottom of the bottle instead of sliding or flowing down; this occurrence is noted as " + ". The least amount of NF concentration that could persuade the gel formation was projected as CIC [35].

\subsubsection{Expansion Coefficient (S\%)}

As per the nature of in situ gels, as a solution transforms into a gel, its volume may expand. This may cause uneasiness in the nasal cavity, owing to its small size. Thus, the expansion coefficient, S\%, was evaluated by mixing $1 \mathrm{~mL}$ DGG solution $(0.5 \%)$ and $0.25 \mathrm{~mL} \mathrm{NF}$ in a graduated test tube and kept in a water bath at $32{ }^{\circ} \mathrm{C}$ (The initial volume $\mathrm{V}_{\mathrm{I}}=1.25 \mathrm{~mL}$ ). About $2 \mathrm{~mL}$ of the optimized formulation was added to the above solution. The Final volume $\left(V_{F}=3.25\right)$, and changes in the volume after gelation $\left(V_{G}\right)$ were noted [36]. $\mathrm{S} \%$ was calculated using the following formula:

$$
(\mathrm{S} \%)=\left(\mathrm{V}_{\mathrm{G}}-\mathrm{V}_{\mathrm{I}}\right) / \mathrm{V}_{\mathrm{I}} \times 100 .
$$

\subsubsection{Rheological Properties}

The apparent viscosity values of the optimized formulation were obtained before and after gelation (after $30 \mathrm{~s}$ ) using a Brookfield Digital Viscometer at $10 \mathrm{rpm}$.

\subsubsection{Gel Strength Measurement}

Gel strength is an indirect sign of the viscosity of a prepared formulation under physiological conditions. After NF was added (neutralization reaction), about $5 \mathrm{~g}$ formulation transformed into a gel. Subsequently, $3.5 \mathrm{~g}$ formulation was positioned on the top of the in situ gel obtained, and the time required for the formulation to reach a depth of $3 \mathrm{~mm}$ in the gel was noted as the gel strength.

\subsection{In Vitro Drug Release Studies}

AMP release from the optimized formulation was determined by using a dialysis bag method. Around $5 \mathrm{~mL}$ formulation was placed into the dialysis bag and then engrossed in a vessel containing $100 \mathrm{~mL}$ phosphate buffer solution $(\mathrm{pH}=6)$ at $37 \pm 1^{\circ} \mathrm{C}$ at $50 \mathrm{rpm}$. Samples were withdrawn for $12 \mathrm{~h}$ at regular intervals of time and analyzed for drug content. 


\subsection{Ex Vivo Permeation Studies}

Fresh nasal tissue carefully collected from goat nasal cavities was provided by a local slaughterhouse. Collected tissue (area of $1.76 \mathrm{~cm}^{2}$ ) was mounted onto a Franz diffusion cell, and $7 \mathrm{~mL}$ phosphate buffer $(\mathrm{pH}=6)$ was filled into the receptor chamber at $37 \pm 1{ }^{\circ} \mathrm{C}$. Pre-incubation time was maintained around $20 \mathrm{~min}$ [37]. After this period, $1 \mathrm{~g}$ of the optimized formulation and $1 \mathrm{~mL}$ pure drug suspension were placed into the donor chamber. At regular intervals of time, $0.5 \mathrm{~mL}$ sample was withdrawn, replaced with $0.5 \mathrm{~mL}$ fresh phosphate buffer $(\mathrm{pH}=6)$, and the drug content in the sample was measured using high-performance liquid chromatography (HPLC) with a column: Phenomenex luna C18 $(250 \times 4.6 \mathrm{~mm}, 5 \mu \mathrm{m})$; mobile phase: $55 / 45$ organic phase $(41 / 18 / 10$ methanol/acetonitrile/tetrahydrofuran)-buffer $\left(2.5 \mathrm{mmol} \mathrm{L}^{-1}\right.$ Ethylene-diamine-tetracetic acidEDTA-2Na); flow rate: $1.0 \mathrm{~mL} \mathrm{~min}^{-1}$; column temperature: $30^{\circ} \mathrm{C}$; detection wavelengths: 383 and $303 \mathrm{~nm}$; injection volume: $20 \mu \mathrm{L}$. Several skin permeation parameters, including the diffusion coefficient (D), enhancement ratio (ER), permeability coefficient and steady state transdermal flux (Jss), were calculated from the permeation data obtained.

\subsection{Nephrotoxicity Studies}

A total of 18 rabbits were acquired from the Beni-Suef Clinical laboratory center, Beni-Suef. Egypt. All conventions were affirmed by the Animal Ethics Committee of the Beni-Suef Clinical Laboratory (Approval NO. 1-02-18, at Jan. 2018) and complied with the Declaration of Helsinki. Grouping of animals and the sample feed are depicted in Figure 1 [38]. Initially, all the acquired animals were adapted at $20 \pm 1{ }^{\circ} \mathrm{C}$ for no less than 14 days under natural climatic conditions $(12 / 12 \mathrm{~h}$ dark/light cycle) with free admittance to water and feed.

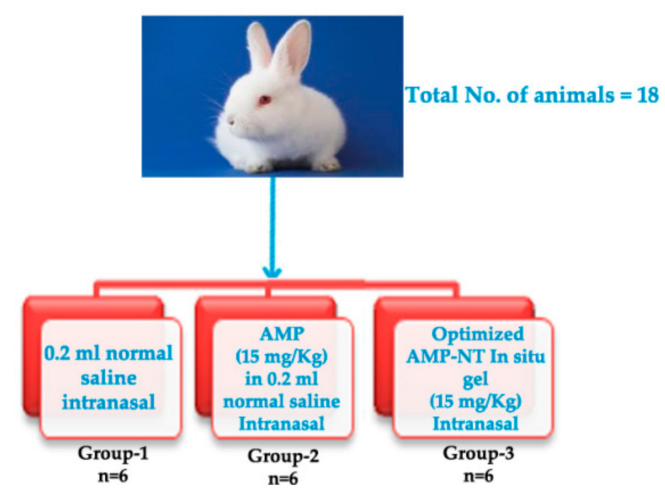

Figure 1. In vivo animal study groups and sample information.

\section{Results and Discussion}

\subsection{Optimization of AMP-NT}

A Box-Behnken design with mixture design was used to explore the impact of the selected variables on minimum particle size, serum creatinine ( $\mathrm{Y} 1$ and $\mathrm{Y} 4$ ), maximum EE, and inhibition zone (Y2 and Y3), [39]. A total of 19 runs were conducted, and the evaluated responses are presented in Table 2. The particle size of all trial batches was found to be in the range of 73 to $210 \mathrm{~nm}$, and EE and inhibition zone were estimated in the range of $58-89 \%$ and $4-28 \mathrm{~mm}$, respectively. The results obtained were statistically evaluated to determine individual responses to the selected variables by applying analysis of variance (ANOVA) and the fx model.

Different models were prepared according to the fit summary of responses (adjusted and predicted R2) and sequential sum of squares (Type-I), as shown in Table 3. In these models, the selected parameters were not aliased in order to find the highest order polynomial [40]. The precision of the models was further studied using the normal probability of studentized residuals, which were those that were scattered closest to the straight line with 
a slight deviation. ANOVA was performed to further evaluate the quantitative association between the responses and variables.

Table 2. Projected trail formulations and their observed responses as per Box-Behnken design.

\begin{tabular}{|c|c|c|c|c|c|c|c|}
\hline Run & $\begin{array}{c}\text { A: Soybean } \\
\text { Lecithin }\end{array}$ & B: Amphotericin B & C: Clove Oil & Particle Size & $\mathrm{EE} \%$ & $\begin{array}{c}\text { Inhibition } \\
\text { Zone }\end{array}$ & $\begin{array}{l}\text { Serum } \\
\text { Creatinine }\end{array}$ \\
\hline & $\mathrm{mg} / \mathrm{mL}$ & $\mathrm{mcg} / \mathrm{mL}$ & $\mathrm{mg} / \mathrm{mL}$ & nm & $\%$ & $\mathbf{m m}$ & $\mathrm{mmol} / \mathrm{L}$ \\
\hline 1 & 0 & -1 & 1 & 120 & 70 & 7 & 0.106 \\
\hline 2 & 0 & -1 & -1 & 130 & 67 & 4 & 0.102 \\
\hline 3 & 0 & 1 & -1 & 190 & 60 & 22 & 0.149 \\
\hline 4 & -1 & 1 & 0 & 110 & 58 & 25 & 0.16 \\
\hline 5 & -1 & 0 & 1 & 91 & 81 & 19 & 0.128 \\
\hline 6 & 1 & 0 & -1 & 170 & 87 & 14 & 0.116 \\
\hline 7 & 1 & 1 & 0 & 210 & 65 & 23 & 0.143 \\
\hline 8 & -1 & 0 & -1 & 100 & 77 & 15 & 0.122 \\
\hline 9 & -1 & -1 & 0 & 73 & 64 & 6 & 0.109 \\
\hline 10 & 0 & 0 & 0 & 154 & 85 & 16 & 0.12 \\
\hline 11 & 0 & 1 & 1 & 179 & 63 & 28 & 0.155 \\
\hline 12 & 1 & -1 & 0 & 140 & 72 & 4 & 0.1 \\
\hline 13 & 1 & 0 & 1 & 164 & 89 & 18 & 0.118 \\
\hline 14 & 0 & 0 & 0 & 156 & 84 & 16 & 0.12 \\
\hline 15 & -1 & -1 & -1 & 80 & 61 & 4 & 0.107 \\
\hline 16 & -1 & 0 & 0 & 96 & 79 & 17 & 0.124 \\
\hline 17 & 0 & 1 & 0 & 185 & 61 & 24 & 0.152 \\
\hline 18 & 0 & -1 & 0 & 126 & 69 & 5 & 0.104 \\
\hline 19 & 1 & 1 & 1 & 204 & 66 & 27 & 0.146 \\
\hline
\end{tabular}

Table 3. Fit summary of responses.

\begin{tabular}{ccccccccc}
\hline & \multicolumn{2}{c}{ PS } & \multicolumn{2}{c}{ EE } & \multicolumn{2}{c}{ Inhibition Zone } & \multicolumn{2}{c}{ Serum Creatinine } \\
\hline Source & $\begin{array}{c}\text { Adjusted } \\
\mathbf{R}^{\mathbf{2}}\end{array}$ & $\begin{array}{c}\text { Predicted } \\
\mathbf{R}^{\mathbf{2}}\end{array}$ & $\begin{array}{c}\text { Adjusted } \\
\mathbf{R}^{\mathbf{2}}\end{array}$ & $\begin{array}{c}\text { Predicted } \\
\mathbf{R}^{\mathbf{2}}\end{array}$ & $\begin{array}{c}\text { Adjusted } \\
\mathbf{R}^{\mathbf{2}}\end{array}$ & $\begin{array}{c}\text { Predicted } \\
\mathbf{R}^{\mathbf{2}}\end{array}$ & $\begin{array}{c}\text { Adjusted } \\
\mathbf{R}^{\mathbf{2}}\end{array}$ & $\begin{array}{c}\text { Predicted } \\
\mathbf{R}^{\mathbf{2}}\end{array}$ \\
\hline Linear & 0.9070 & 0.8700 & -0.0540 & -0.4099 & 0.9859 & 0.9799 & 0.9511 & 0.9364 \\
2FI & 0.8931 & 0.7941 & -0.2386 & -1.2717 & 0.9846 & 0.9692 & 0.9416 & 0.8989 \\
Quadratic & $\mathbf{0 . 9 9 3 6}$ & $\mathbf{0 . 9 7 1 5}$ & $\mathbf{0 . 9 9 6 7}$ & $\mathbf{0 . 9 9 1 1}$ & $\mathbf{0 . 9 9 7 8}$ & $\mathbf{0 . 9 9 3 5}$ & $\mathbf{0 . 9 9 4 6}$ & $\mathbf{0 . 9 8 2 6}$ \\
Cubic & 0.9995 & & 0.9977 & & 0.9994 & & 0.9996 \\
\hline
\end{tabular}

PS: Particle size; EE: Entrapement Effecieny.

\subsection{Response I}

Among the applied models, the quadratic model exhibited the maximum Adju. R2 (0.9936) and Pred. R2 (0.9715) values and, thus, was chosen over the linear, 2FI, and cubic models. Furthermore, this was supported by a significant model F-value (41.64) and there is only $0.01 \%$ chance that an F-value (6.40) this large could occur due to noise. A non-significant lack of fit with a $p$ value of 0.2969 suggests that the model is efficient. The coefficient of variation $(\mathrm{CV})$, which helps to determine the reproducibility of the model, was found to be $<10 \%(2.42 \%)$.

Additionally, adequate precision is determined according to the signal to noise ratio, where a ratio larger than 4 is desired. Herein, the ratio of 54.133 obtained confirms the ample signal to navigate the design space [41].

The polynomial equation can be further applied to predict the response from any given concentrations of independent variables and generate the relation using multiple regression analysis. From this, the response for any given level of selected factors can be predicted to identify the relative impact between them by comparing the coefficients.

ANOVA results revealed the significant statistical relationship between the components and responses at a 95\% confidence level. Both $p$ values of ANOVA and polynomial 
equations were used to estimate the true effect of variables, where $p$ values less than 0.0500 indicate that the model terms are significant. According to the ANOVA results, Response I was significantly affected by three independent factors via a synergistic effect ( $p$-value of $<0.0001$ ) $[42,43]$ with A having highest magnitude of 38.46 (Table 4); thus, factors $C$ and the polynomial terms of A affect the response antagonistically. The final equations in terms of the coded factors was determined to be:

Particle size $=+155.09+38.46 \mathrm{~A}+28.44 \mathrm{~B}-4.58 \mathrm{C}+8.44 \mathrm{AB}+0.9412 \mathrm{AC}-0.0588 \mathrm{BC}-22.28 \mathrm{~A}^{2}+0.6754 \mathrm{~B}^{2}-1.19 \mathrm{C}^{2}$

Table 4. Analysis of variance (ANOVA) results for three responses.

\begin{tabular}{|c|c|c|c|c|c|c|c|c|}
\hline \multirow{3}{*}{ Term } & \multicolumn{6}{|c|}{ Responses } & & \\
\hline & \multicolumn{2}{|c|}{ PS } & \multicolumn{2}{|c|}{ Steady State flux (JSS) } & \multicolumn{2}{|c|}{ Inhibition Zone } & \multicolumn{2}{|c|}{ Serum Creatinine } \\
\hline & F-Value & $p$ Value & F-Value & $p$ Value & F-Value & $p$ Value & F-Value & $p$ Value \\
\hline Model & 310.83 & $<0.0001$ & 598.28 & $<0.0001$ & 915.93 & $<0.0001$ & 367.49 & $<0.0001$ \\
\hline A-Soybean Lecithin & 1293.11 & $<0.0001$ & 536.19 & $<0.0001$ & 33.64 & 0.0003 & 136.07 & $<0.0001$ \\
\hline B-Amphotericin B & 790.91 & $<0.0001$ & 401.96 & $<0.0001$ & 7044.42 & $<0.0001$ & 3033.65 & $<0.0001$ \\
\hline C-Clove oil & 16.99 & 0.0026 & 66.37 & $<0.0001$ & 304.34 & $<0.0001$ & 18.60 & 0.0020 \\
\hline $\mathrm{AB}$ & 29.26 & 0.0004 & 1.10 & 0.3224 & 0.1094 & 0.7484 & 8.47 & 0.0173 \\
\hline $\mathrm{AC}$ & 0.3638 & 0.5613 & 3.94 & 0.0785 & 0.1094 & 0.7484 & 1.96 & 0.1952 \\
\hline $\mathrm{BC}$ & 0.0014 & 0.9708 & 0.0119 & 0.9155 & 15.12 & 0.0037 & 0.7506 & 0.4088 \\
\hline $\mathrm{A}^{2}$ & 174.48 & $<0.0001$ & 4.27 & 0.0688 & 0.3428 & 0.5726 & 0.2112 & 0.6568 \\
\hline $\mathrm{B}^{2}$ & 0.1513 & 0.7063 & 4141.47 & $<0.0001$ & 56.84 & $<0.0001$ & 113.94 & $<0.0001$ \\
\hline$C^{2}$ & 0.5316 & 0.4845 & & & & & & \\
\hline Lack of Fit & 6.40 & 0.2969 & 0.6371 & 0.7544 & & & & \\
\hline
\end{tabular}

\subsection{Response II}

The quadratic model was selected for Response II on basis of the maximum Adju. R2 (0.9967) and Pred. R2 (0.9911) values in comparison to the other models. The model F-value (598.28) was found to be significant with only a $0.01 \%$ chance the large F-value is due to noise. The CV value was found to be $<10 \%(0.8142 \%)$, thus confirming the reproducibility of the model. The adequate precision ratio of 74.659 indicates an ample signal to navigate the design space [41].

Both $p$ values of ANOVA and polynomial equations were used to estimate the true effect of variables. Per ANOVA results, Response II was affected significantly by A and $C$ factors via a synergistic effect ( $p$ value $<0.0001)[39,40]$ with A having the highest magnitude of 38.46 (Table 4), while factors B and the polynomial terms of B affect the response antagonistically. The final equation in terms of coded factors is:

$E E \%=+84.30+4.23 \mathrm{~A}-3.46 \mathrm{~B}+1.55 \mathrm{C}-0.2791 \mathrm{AB}-0.5291 \mathrm{AC}-0.0291 \mathrm{BC}-0.5952 \mathrm{~A}^{2}-19.08 \mathrm{~B}^{2}-0.2263 \mathrm{C}^{2}$

\subsection{Response III}

Maximum Adju. R2 of 0.9978 and Pred. R2 of 0.9935 were determined for the quadratic model or Response I. The highest model F-value of 915.93 indicates that there is only a $0.01 \%$ chance that an F-value this large could be due to noise. As required, the CV value of $2.51 \%$ confirms the reproducibility of the selected model. Both $p$ values of ANOVA and polynomial equations were used to estimate the true effect of the variables, which reveal that Response III was significantly affected by B, C, and BC factors via synergistic effect ( $p$ value $<0.0001$ ) with the highest magnitude of 38.46 for factor A (Table 4). Factors A and polynomial terms of $\mathrm{B}$ and $\mathrm{C}$ affect the response antagonistically. The final equation in terms of coded factors is: 


\subsection{Response IV}

The model F-value of 367.49, maximum Adju. R2 of 0.9946, and Pred. R2 of 0.9826 support the selection of the quadratic model for the generation of polynomial equations. The adequate precision of 55.1604 indicates an adequate signal to navigate the design space. As per the ANOVA results, Response IV was significantly affected by B, C, and $\mathrm{B}^{2}$ factors via synergistic effect $(p$ value $<0.0001$ ) $[39,40]$ with the highest magnitude of 38.46 for factor A (Table 4). Factors A and AB affect the response antagonistically.

$$
\begin{gathered}
\text { Inhibition zone }=+16.09-0.7066 \mathrm{~A}+9.67 \mathrm{~B}+2.21 \mathrm{C}-0.0588 \mathrm{AB}-0.0588 \mathrm{AC} \\
+0.6912 \mathrm{BC}-0.1125 \mathrm{~A}^{2}-1.49 \mathrm{~B}^{2}+0.5583 \mathrm{C}^{2} \\
\text { Serum Creatinine }=+0.1198-0.0053 \mathrm{~A}+0.0236 \mathrm{~B}+0.0020 \mathrm{C}-0.0019 \mathrm{AB} \\
-0.0009 \mathrm{AC}+0.0006 \mathrm{BC}+0.0003 \mathrm{~A}^{2}+0.0079 \mathrm{~B}^{2}+0.0007 \mathrm{C}^{2}
\end{gathered}
$$

RSM was applied to analyze the impact of these selected factors, and the respective contour plots and 3-dimensional graphs are shown in Figure 2. The results confirm the significant effect of the selected variables on particle size. Experimental runs with a smaller soybean concentration resulted in the formation of smaller-sized particles, which is in agreement with previous research [44]. The surfactant hydrophilic-lipophilic (HLB) value in the range of 12-16 is considered ideal for the production of nanotransferosomes. In contrast, HLB of 6-11 in soybean favors the formation of nano-drug delivery systems with smaller particle size. This is because smaller particles can more effectively reach the target tissues through systemic circulation and easily overcome the barrier problems associated with intranasal delivery. Conversely, the distribution of moderate size particles can lessen the risk of embolism. Moreover, higher levels of soybean concentration can enhance the entrapment efficacy and inhibition zone, further influencing the serum creatinine levels in an antagonistic way. According to the results obtained, the soybean and AMP concentrations largely impacted all the selected responses but in different ways [45]. Specifically, particle size, inhibition zone, serum creatinine, and EE were affected by AMP in a synergistic and antagonistic manner. As stated in literature, low oil levels can increase the particle size since the coalescence of oil droplets and added surfactant concentration can overcome the permeation problem. Conversely, increasing the proportion of surfactant in the nanotransfersomes can help in particle size reduction, while clove oil synergistically affects all other responses.

Lastly, the formulation of AMP-NT was optimized by setting the desired goals for each response and simultaneously applying the global desirability function (D). On the basis of these criteria, the desirability plot was generated with a $D$ value of 0.634 (Figure 3). In conclusion, the optimized formulation was determined to be $300 \mathrm{mg} / \mathrm{mL}$ soybean lecithin, $200 \mathrm{mg} / \mathrm{mL}$ amphotericin $\mathrm{B}$, and $150 \mathrm{mg} / \mathrm{mL}$ clove oil, resulting in a particle size of $155.09 \mathrm{~nm}, 84.30 \% \mathrm{EE}$, inhibition zone of $16.0889 \mathrm{~mm}$, and $0.1197 \mathrm{mmol} / \mathrm{L}$ serum creatinine. those results showed no significant difference with the predicted results shown in Figure 3. For example the actual value for serum creatinine is $0.1197 \mathrm{mmol} / \mathrm{L}$ while the predicted value in the figure is $0.1169 \mathrm{mmol} / \mathrm{L}$, which indicated no significant difference between predicted and actual values. 


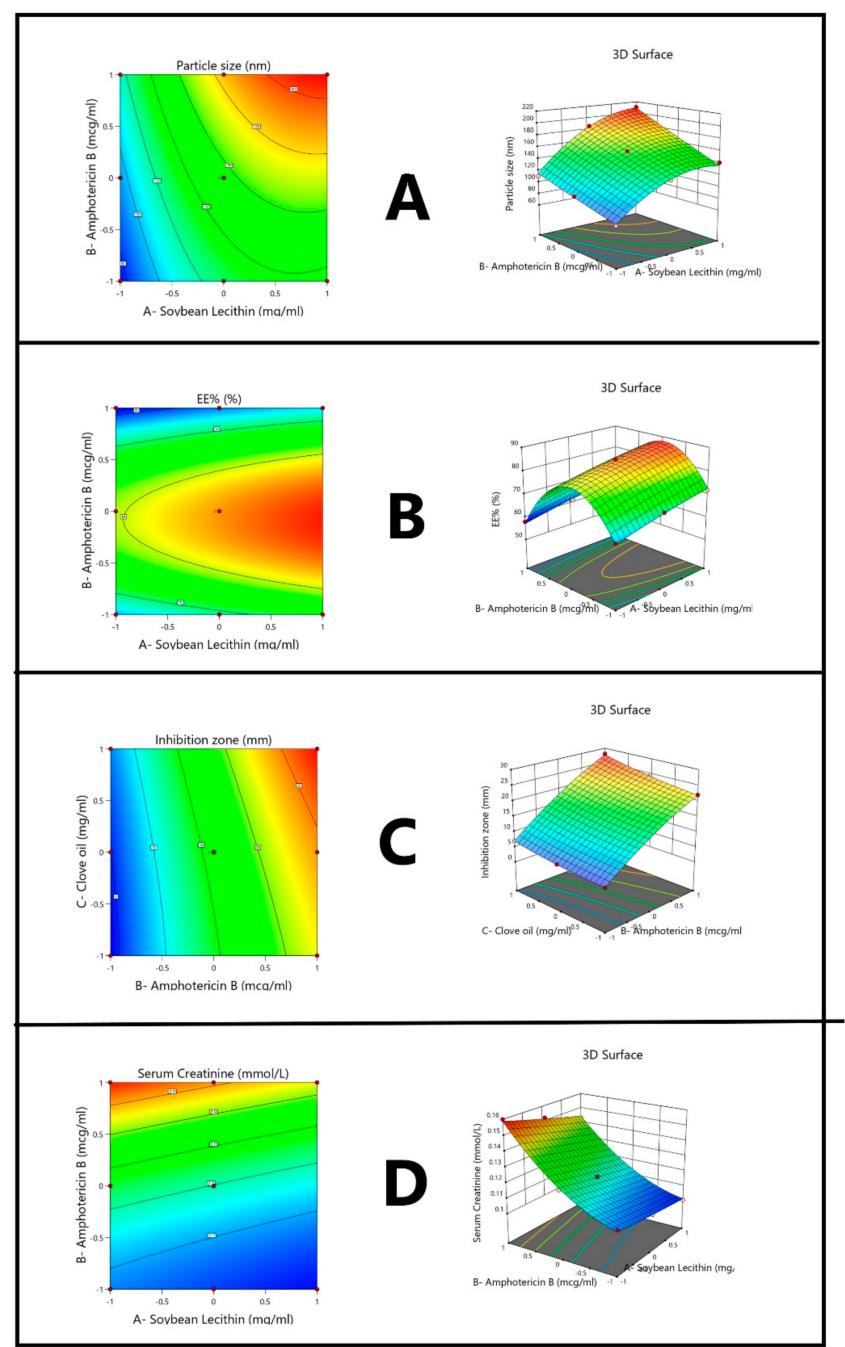

Figure 2. Contour and 3-dimensional response surface graphs of (A) particle size, (B) entrapment efficacy, (C) inhibition zone, and (D) serum creatinine.
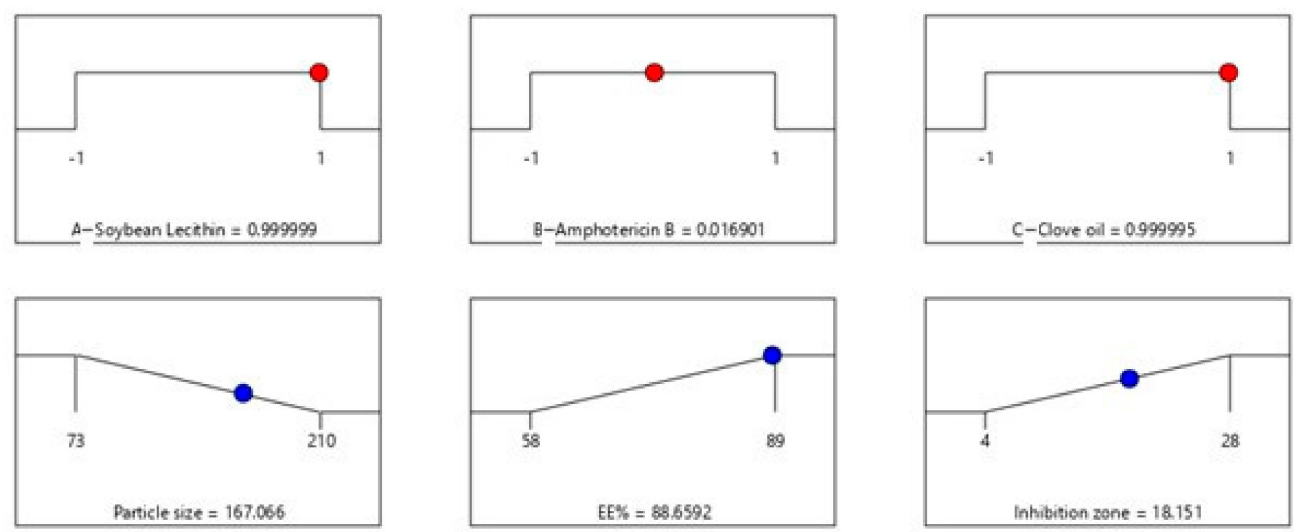

Desirability $=0.634$

Solution 1 out of 55

Figure 3. Desirability graph for optimization of AMP-NT. 


\subsection{Evaluation of AMP-NT In Situ Gels}

The optimized formulation of NT was used to further prepare the AMP-NT in situ gels and evaluate various parameters. The results are depicted in Table 5. AMP-NT in situ gel had a clear appearance. The gelling capacity was found to be positive, and the quick gel transformation indicates the transformation of the formulation into gel was rapid for prepared in situ gel. A noticeable increase in the viscosity before and after gelation $(2.93-34.26 \mathrm{cP})$ can be attributed to the presence of DCG in the formulation. However, this increased viscosity of the prepared formulation may limit its retention time in the nasal cavity since transformation into the gel may cause uneasiness in the nose. Comparatively, the expansion coefficient of the AMP-NT in situ gel was found to be $2.7 \%$, indicating very slight expansion and, thus, minimal discomfort in patients [46]. The optimal gel should allow for easy administration but should not leak from the nasal cavity; hence, gel strength is a vital parameter to consider when formulating the in situ gel. Herein, the gel strength was determined to be $38.5 \mathrm{~s}$, which is in the acceptable range of 25-50 s. Gel strength less than $25 \mathrm{~s}$ can lead to rapid erosion, and that greater than $50 \mathrm{~s}$ can cause much discomfort.

Table 5. Evaluation of optimized AMP-NT in situ gel.

\begin{tabular}{ccc}
\hline Formulation & Parameter & Result \\
\hline & Gelling Capacity & + ve \\
& CIC\% $\%$ & 0.17 \\
AMP-NT in situ gel & S\% & 2.7 \\
& Viscosity before gellation $(\mathrm{cp})$ & $2.93 \pm 0.37$ \\
& Viscosity after gellation $(\mathrm{cp})$ & $34.26 \pm 3.01$ \\
& Gel strength & $38.5 \mathrm{~s}$ \\
\hline
\end{tabular}

CIC\%: Critical Ionic Concentration; S\%: Expansion Coeffecient.

\subsection{In Vitro Release}

Figure 4 shows the drug-release profile from the aqueous suspension and optimized AMP-NT in situ gel. Incomplete drug release (79.25\% AMP) was observed in both the aqueous suspension and AMP in situ gel even at the end of $12 \mathrm{~h}$, which may be due to the incomplete absorption of AMP in the selected formulations. Enhanced drug absorption was observed from nanotransferosomes, primarily credited to the reduced particle size. According to the inflection points observed in the release profile, the initial drug release was rapid due to incomplete gel formation. Thereafter, gelation further caused slow drug release from the in situ gel and reached a steady state concentration with remaining formulations.

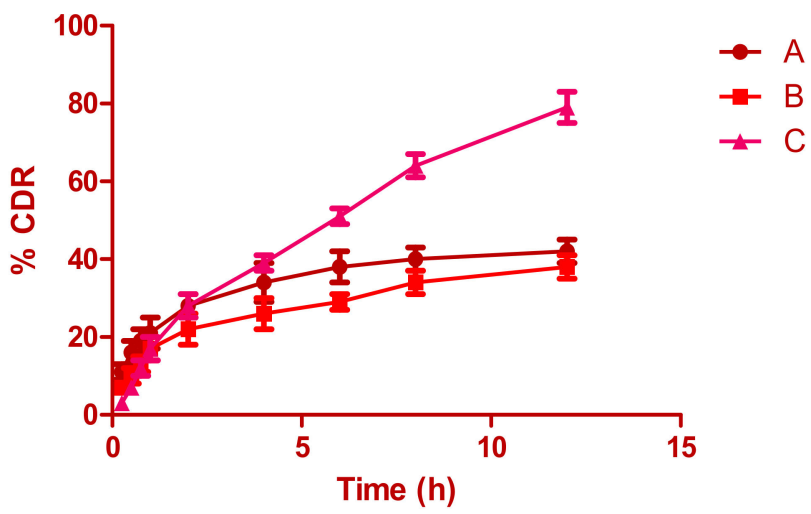

Figure 4. In vitro drug release profile from (A) amphotericin B released from aqueous suspension, (B) amphotericin $B$ released from in situ gel loaded with drug aqueous suspension, and $(C)$ amphotericin $B$ released from optimized nanotransferosomal in situ gel. 


\subsection{Ex Vivo Permeation}

Ex vivo permeation results of the aqueous suspension, optimized formula, and optimized formula prepared without clove oil through nasal membrane are presented in Table 6. A significant difference between the evaluated parameters was observed in all formulations.

Table 6. Ex vivo permeation results.

\begin{tabular}{cccc}
\hline Permeation Parameters & Optimized Formula & $\begin{array}{c}\text { Optimized Formula } \\
\text { Prepared without Clove Oil }\end{array}$ & Aqueous Suspension \\
\hline Cumulative amount permeated $\left(\mu \mathrm{g} / \mathrm{cm}^{2}\right)$ & $8915 \pm 808$ & $4822 \pm 406$ & $1813 \pm 152$ \\
Cumulative percent permeated & $79.45 \%$ & $37.2 \%$ & $1.254 \pm 0.31$ \\
Steady state flux, Jss, $\left(\mu \mathrm{g} / \mathrm{cm}^{2} \cdot \mathrm{min}\right)$ & $4.933 \pm 1.02$ & $3.011 \pm 1.11$ & $0.411 \times 10^{-3}$ \\
Permeability coefficient, $\mathrm{P}(\mathrm{cm} / \mathrm{min})$ & $3.101 \times 10^{-3}$ & $1.411 \times 10^{-3}$ & $5.66 \times 10^{-5}$ \\
Diffusion coefficient, $\mathrm{D},\left(\mathrm{cm}^{2} / \mathrm{min}\right)$ & $16.22 \times 10^{-5}$ & $11.18 \times 10^{-5}$ & - \\
Enhancement factor $(\mathrm{EF})$ & 5.562 & 3.013 & - \\
\hline
\end{tabular}

In the optimized formulation with clove oil, $79.45 \%$ AMP permeated through the nasal membrane in accordance with the dissolution results, while only $37.2 \%$ permeated in the optimized formulation without clove oil, confirming the importance of clove oil.

Moreover, the prepared AMP-NT has the potential to penetrate and be retained in the nasal tissue, thus altering the permeation pathways of lipids. Moreover, the hydrophobic part of AMP-NT can further hydrate the internal area of the nasal cavity and plays a vital role in the uptake of the drug loaded by the tissue [47].

\subsection{Nephrotoxicity Studies}

Table 7 presents the various renal function parameters that were measured from rabbit plasma treated with amphotericin B aqueous suspension and the optimized amphotericin $B$ optimized nanotransferosomal in situ gel against the control group. The results of the group treated with amphotericin B aqueous suspension indicated significant changes nearly in all measured responses compared to the control group. While the results of the group treated with amphotericin B optimized nanotransferosomal in situ gel showed no significant difference in all measured responses compared to the control group

Table 7. Various renal functional parameters evaluated from rabbit plasma for control and samples administered.

\begin{tabular}{|c|c|c|c|c|c|c|c|}
\hline & Parameters & $\begin{array}{l}\text { Glucose } \\
(\mathrm{mmol} / \mathrm{L})\end{array}$ & $\begin{array}{l}\text { Creatinine } \\
(\mathrm{mmol} / \mathrm{L})\end{array}$ & $\begin{array}{c}\text { Urea } \\
(\mathrm{mmol} / \mathrm{L})\end{array}$ & $\begin{array}{l}\text { Calcium } \\
(\mathrm{mmol} / \mathrm{L})\end{array}$ & $\begin{array}{l}\text { Sodium } \\
(\mathrm{mmol} / \mathrm{L})\end{array}$ & $\begin{array}{r}\text { Potassium } \\
(\mathrm{mmol} / \mathrm{L})\end{array}$ \\
\hline \multirow[t]{3}{*}{ Control group } & Day 1st & $6.1 \pm 0.4$ & $0.1 \pm 0.01$ & $6.5 \pm 1.1$ & $3.4 \pm 0.2$ & $139 \pm 3$ & $3.8 \pm 0.3$ \\
\hline & Day 5th & $6.4 \pm 0.2$ & $0.1 \pm 0.01$ & $6.3 \pm 0.9$ & $3.3 \pm 0.2$ & $137 \pm 2$ & $3.8 \pm 0.4$ \\
\hline & Day 10th & $6.3 \pm 0.3$ & $0.11 \pm 0.01$ & $6.9 \pm 0.6$ & $3.3 \pm 0.3$ & $141 \pm 5$ & $3.7 \pm 0.3$ \\
\hline \multirow{3}{*}{$\begin{array}{l}\text { Amphotericin B aqueous } \\
\text { suspension group }\end{array}$} & Day 1st & $6.1 \pm 0.4$ & $0.1 \pm 0.01$ & $6.3 \pm 0.4$ & $3.2 \pm 0.2$ & $138 \pm 6$ & $3.8 \pm 0.2$ \\
\hline & Day 5th & $5.4 \pm 0.2 *$ & $0.13 \pm 0.01 *$ & $6.1 \pm 0.3$ & $2.88 \pm 0.2$ & $147 \pm 4^{*}$ & $4.2 \pm 0.2$ \\
\hline & Day 10th & $4.95 \pm 0.1 *$ & $0.16 \pm 0.02 *$ & $5.2 \pm 0.3 *$ & $2.11 \pm 0.4 *$ & $159 \pm 4$ * & $4.8 \pm 0.3$ * \\
\hline \multirow{3}{*}{$\begin{array}{c}\text { Amphotericin B optimized } \\
\text { nanotransferosomal in } \\
\text { situ gel group }\end{array}$} & Day 1st & $6.1 \pm 0.3$ & $0.1 \pm 0.01$ & $6.4 \pm 0.3$ & $3.3 \pm 0.3$ & $138 \pm 4$ & $3.8 \pm 0.2$ \\
\hline & Day 5th & $6.2 \pm 0.1$ & $0.11 \pm 0.01$ & $6.3 \pm 0.1$ & $3.0 \pm 0.2$ & $141 \pm 3$ & $4.0 \pm 0.2$ \\
\hline & Day 10th & $6.05 \pm 0.1$ & $0.12 \pm 0.01$ & $6.3 \pm 0.2$ & $2.9 \pm 0.2$ & $144 \pm 3$ & $4.1 \pm 0.3$ \\
\hline
\end{tabular}

$\left(^{*}\right) p$ value $<0.05$ indicates a significant difference between parameters in comparison with the control group.

The glomerular filtration rate is used to measure the excretion of a drug in urine [48]. In the current study, the large glomerular rate indicates that a large concentration of the optimized formulation was found in the urine. 
Moreover, a decrease in the serum calcium levels in the test samples may be attributed to hypoproteinaemia, while a slight increase in sodium and potassium levels was observed with the optimized AMP-NT in situ gel.

\section{Conclusions}

In the present study, an AMP-NT in situ gel was prepared to study its effect against Aspergillus flavus in the nasal cavity. A Box-Behnken design, ANOVA, and polynomial equations were applied to optimize the concentrations of various parameters by statistical methodology. The optimized formulation was determined to be $300 \mathrm{mg} / \mathrm{mL}$ soybean lecithin, $200 \mathrm{mg} / \mathrm{mL}$ amphotericin B, and $100 \mathrm{mg} / \mathrm{mL}$ clove oil, which further achieved a minimum particle size and serum creatinine levels and maximum EE and zone of inhibition. The optimized AMP-NT was further prepared into an in situ gel system, optimized for suitable intranasal delivery, and evaluated for various in vitro, ex vivo, and in vivo parameters. In vitro, ex vivo permeation, and nephrotoxic studies confirm the enhanced percentage of drug permeation into the nasal tissues, owing to the presence of clove oil.

Author Contributions: Conceptualization, and methodology, K.M.H.; software, and validation, N.A.A.; formal analysis, investigation, resources, and data curation, K.M.H.; writing-original draft preparation, N.A.A.; writing-review and editing, K.M.H.; visualization, N.A.A.; supervision, and project administration, K.M.H.; All authors have read and agreed to the published version of the manuscript.

Funding: This research work was funded by Institutional Fund Projects under grant no. (IFPHI-149166-2020).

Institutional Review Board Statement: The study was conducted according to the guidelines of the Declaration of Helsinki, and approved by the Animal Ethics Committee of the Beni-Suef Clinical Laboratory (Approval NO. 1-02-18, at Jan.2018).

Data Availability Statement: Not applicable.

Acknowledgments: This research work was funded by Institutional Fund Projects under grant no. (IFPHI-149-166-2020). Therefore, authors gratefully acknowledge technical and financial support from the Ministry of Education and King Abdulaziz University, DSR, Jeddah, Saudi Arabia.

Conflicts of Interest: The authors declare no conflict of interest.

\section{References}

1. Vennewald, I.; Henker, M.; Klemm, E.; Seebacher, C. Fungal colonization of the paranasal sinuses. Mycoses 1999, 42, 33-36. [CrossRef] [PubMed]

2. Taj-Aldeen, S.J.; Hilal, A.A.; Chong-Lopez, A. Allergic Aspergillus flavus rhinosinusitis: A case report from Qatar. Eur. Arch. Oto-Rhino-Laryngol. 2003, 260, 331-335. [CrossRef] [PubMed]

3. Schell, W.A. Unusual fungal pathogens in fungal rhinosinusutis. Otolaryngol. Clin. N. Am. 2000, 33, 367-373. [CrossRef]

4. Houser, S.M.; Corey, J.P. Allergic fungal rhinosinusitis. Otolaryngol. Clin. N. Am. 2000, 33, 399-408. [CrossRef]

5. Schell, W.A. Histopathology of fungal rhinosinusitis. Otolaryngol. Clin. N. Am. 2000, 33, 251-276. [CrossRef]

6. Stone, N.R.; Bicanic, T.; Salim, R. Hope, Liposomal amphotericin B (AmBisome ${ }^{\circledR}$ ): A review of the pharmacokinet-ics, pharmacodynamics, clinical experience and future directions. Drugs 2016, 76, 485-500. [CrossRef]

7. Sokolsky-Papkov, M.; Domb, A.J.; Golenser, J. Impact of Aldehyde Content on Amphotericin B-Dextran Imine Conjugate Toxicity. Biomacromolecules 2006, 7, 1529-1535. [CrossRef]

8. Nahar, M.; Jain, N.K. Preparation, Characterization and Evaluation of Targeting Potential of Amphotericin B-Loaded Engineered PLGA Nanoparticles. Pharm. Res. 2009, 26, 2588-2598. [CrossRef]

9. Tiyaboonchai, W.; Limpeanchob, N. Formulation and characterization of amphotericin B-chitosan-dextran sulfate nanoparticles. Int. J. Pharm. 2007, 329, 142-149. [CrossRef]

10. Asthana, S.; Jaiswal, A.K.; Gupta, P.K.; Dube, A.; Chourasia, M.K. Th-1 biased immunomodulation and synergistic antileishmanial activity of stable cationic lipid- polymer hybrid nanoparticle: Biodistribution and toxicity assess-ment of encapsulated amphotericin B. Eur. J. Pharm. Biopharm. 2015, 89, 62-73. [CrossRef]

11. Vyas, S.; Katare, Y.; Mishra, V.; Sihorkar, V. Ligand directed macrophage targeting of amphotericin B loaded lipo-somes. Int. J. Pharm. 2000, 210, 1-14. [CrossRef]

12. Yang, Z.L.; Li, X.R.; Yang, K.W.; Liu, Y. Amphotericin B-loaded poly (ethylene glycol)- poly (lactide) micelles: Prepa-ration, freeze-drying, and in vitro release. J. Biomed. Mater. Res. 2008, 85, 539-546. [CrossRef] [PubMed] 
13. Butani, D.; Yewale, C.; Misra, A. Topical Amphotericin B solid lipid nanoparticles: Design and development. Colloids Surfaces B Biointerfaces 2016, 139, 17-24. [CrossRef] [PubMed]

14. Jain, K.; Verma, A.K.; Mishra, P.R.; Jain, N.K. Characterization and evaluation of amphotericin B loaded MDP conju-gated poly (propylene imine) dendrimers. Nanomedicine 2015, 11, 705-713. [CrossRef] [PubMed]

15. Eldem, T.; Arican-Cellat, N. Determination of amphotericin B in human plasma using solid-phase extraction and high-performance liquid chromatography. J. Pharm. Biomed. Anal. 2001, 25, 53-64. [CrossRef]

16. Mistro, L.S.; Rosa, B.; Gomes, L.; Badaró, M.R. Cost-effectiveness of caspofunging versus liposomal ampho-tericin B in the treatment of systemic fungal infections: A systematic review of economic analyses. Expert Rev. Phar-Macoecon. Outcomes Res. 2016, 16, 465-473. [CrossRef]

17. Clemons, K.V.; Stevens, D.A. Comparative efficacies of four amphotericin B formulations—Fungizone, amphotec (amphocil), ambisome, and abelcet-Against systemic murine aspergillosis. Antimicrob. Agents Chemother. 2004, 48, 1047-1050. [CrossRef]

18. Tufteland, M.L.; Selitrennikoff, C.P.; Ryan, R.O. Nanodisks protect amphotericin B from ultraviolet light and oxida-tion-induced damage. Pest Manag. Sci. 2009, 65, 624-628. [CrossRef]

19. Hong, C.H.; Hur, S.K.; Oh, O.J.; Kim, S.S.; Nam, K.A.; Lee, S.K. Evaluation of natural products on inhibition of inducible cy-clooxygenase (COX-2) and nitric oxide synthase (iNOS) in cultured mouse macrophage cells. J. Ethnopharmacol. 2002, 83, 153-159. [CrossRef]

20. Jadhav, B.K.; Khandelwal, K.R.; Ketkar, A.R.; Pisal, S.S. Formulation and evaluation of mucoadhesive tablets contain-ing eugenol for the treatment of periodontal diseases. Drug Dev. Ind. Pharm. 2004, 30, 195-203. [CrossRef]

21. Goswami, D.S. Permeation enhancer for TDDS from natural and synthetic sources: A review. J. Biomed. Pharm. Res. 2013, 2, 19-29.

22. Scognamiglio, I.; De Stefano, D.; Campani, V.; Mayol, L.; Carnuccio, R.; Fabbrocini, G.; Ayala, F.; La Rotonda, M.I.; De Rosa, G. Nanocarriers for topical administration of resveratrol: A comparative study. Int. J. Pharm. 2013, 440, 179-187. [CrossRef] [PubMed]

23. Zheng, W.; Fang, X.-Q.; Wang, L.-L.; Zhang, Y.-J. Preparation and quality assessment of itraconazole transfersomes. Int. J. Pharm. 2012, 436, 291-298. [CrossRef] [PubMed]

24. Chaudharya, H.; Kohlib, K.; Kumara, V.K. Nano-transfersomes as a novel carrier for transdermal delivery. Int. J. Pharm. 2013, 454, 367-380. [CrossRef]

25. Naveen, N.R.; Gopinath, C.; Rao, D.S. Design expert supported mathematical optimization of repaglinide gastrore-tentive floating tablets: In vitro and in vivo evaluation, Future. J. Pharm. Sci. 2017, 3, 140-147.

26. Xu, X.; Jha, A.K.; Harrington, D.A.; Farach-Carson, M.C.; Jia, X. Hyaluronic acid-based hydrogels: From a natural polysaccharide to complex networks. Soft Matter. 2012, 8, 3280-3294. [CrossRef]

27. Hassan, A.H.; Hosny, K.M.; Murshid, Z.A.; Alhadlaq, A.; Yamani, A.; Naguib, G.; Alkhalidi, H.M.; Afify, A.R. Controlled release of injectable liposomal in situ gel loaded with recombinant human bone morphogenetic protein-2 for the repair of alveolar bone clefts in rabbits. J. Liposome Res. 2016, 26, 148-155.

28. Qushawy, M.; Nasr, A.; Abd-Alhaseeb, M.; Swidan, S.A. Design, Optimization and Characterization of a Transfersomal Gel Using Miconazole Nitrate for the Treatment of Candida Skin Infections. Pharmaceutics 2018, 10, 26. [CrossRef]

29. Khajeh, M. Application of Box-Behnken design in the optimization of a magnetic nanoparticle procedure for zinc determination in analytical samples by inductively coupled plasma optical emission spectrometry. J. Hazard. Mater. 2009, 172, 385-389. [CrossRef]

30. Guo, J.; Ping, Q.-N.; Sun, G.; Jiao, C. Lecithin vesicular carriers for transdermal delivery of cyclosporin A. Int. J. Pharm. 2000, 194, 201-207. [CrossRef]

31. Maghraby, G.M.M.E.; Williams, A.C.; Barry, B.W. Skin delivery from ultradeformable liposomes: Refinement of surfac-tant concentration. J. Pharm. Pharmacol. 1999, 51, 1123-1134. [CrossRef] [PubMed]

32. Sharma, R.; Ahuja, M.; Kaur, H. Thiolated pectin nanoparticles: Preparation, characterization and ex vivo corneal permeation study. Carbohydr. Polym. 2012, 87, 1606-1610. [CrossRef]

33. Bhatia, M.; Ahuja, M. Psyllium arabinoxylan: Carboxymethylation, characterization and evaluation for nanopartic-ulate drug delivery. Int. J. Biol. Macromol. 2015, 72, 495-501. [CrossRef] [PubMed]

34. Kurakula, M.; Ahmed, A.T. Co-Delivery of Atorvastatin Nanocrystals in PLGA based in situ Gel for An-ti-Hyperlipidemic Efficacy. Curr. Drug Deliv. 2015, 13, 211-220. [CrossRef] [PubMed]

35. Hosny, K.M.; Rizg, W.Y.; Khallaf, R.A. Preparation and Optimization of In Situ Gel Loaded with Rosuvastatin-Ellagic Acid Nanotransfersomes to Enhance the Anti-Proliferative Activity. Pharmaceutics 2020, 12, 263. [CrossRef]

36. Tornesello, A.L.; Buonaguro, L.; Tornesello, M.L.; Buonaguro, F.M. Formulation and evaluation of in situ gelling systems for intranasal admin-istration of gastrodin. AAPS PharmSciTech 2011, 12, 1102-1109.

37. Campanero, M.A.; Escolar, M.; Arangoa, M.A. Development of a chromatographic method for the determination of saquinavir in plasma samples of HIV patients. Biomed. Chrom. 2001, 16, 7-12. [CrossRef]

38. Elsayed, M.G.; Elkomy, A.A.; Gaballah, M.; Elbadawy, M. Nephrotoxicity of cefepime a new cephalosporin antibi-otic in rats. J. Pharmacol. Pharm. 2014, 5, 33.

39. Vyas, A.; Saraf, S.; Saraf, S. Encapsulation of cyclodextrin complexed simvastatin in chitosan nanocarriers: A novel technique for oral delivery. J. Incl. Phenom. Macrocycl. Chem. 2009, 66, 251-259. [CrossRef]

40. Kurakula, M.; Naveen, N.R. In Situ Gel Loaded with Chitosan-Coated Simvastatin Nanoparticles: Promising Delivery for Effective Anti-Proliferative Activity against Tongue Carcinoma. Mar. Drugs 2020, 18, 201. [CrossRef] 
41. Hosny, K.M.; Aldawsari, H.M.; Bahmdan, R.H.; Sindi, A.M.; Kurakula, M.; Alrobaian, M.M.; Aldryhim, A.Y.; Alkhalidi, H.M.; Bahmdan, H.H.; Khallaf, R.A.; et al. Preparation, Optimization, and Evaluation of Hyaluronic Acid-Based Hydrogel Loaded with Miconazole Self-Nanoemulsion for the Treatment of Oral Thrush. AAPS PharmSciTech 2019, 20, 297. [CrossRef] [PubMed]

42. Kurakula, M.; Ahmad, O.A.A.; Fahmy, U.A.; Ahmed, T.A. Solid lipid nanoparticles for transdermal delivery of avanafil: Optimization, formulation, in-vitro and ex-vivo studies. J. Liposome Res. 2016, 26, 288-296. [CrossRef] [PubMed]

43. Mallamma, T.; Bharathi, D.R.; Lakshmi, R.G.; Vyjayanthimala, T.; Nagasubbareddy, J.; Naveen, R. Etoposide-loaded na-noparticles made from poly-e-caprolactone (PCL): Formulation, characterization, in vitro drug release for controlled drug delivery system. Int. J. Biopharm. 2014, 5, 5-12.

44. Tahir, M.; Anwaar, A.; Zaheer, A.; Ahmad, M.S. Optimization of soya lecithin and Tween 80 based novel vitamin D nanoemulsions prepared by ultrasonication using response surface methodology. Food Chem. 2019, 289, 664-670.

45. Hosny, K.M.; Aljaeid, B.M. Sildenafil citrate as oral solid lipid nanoparticles: A novel formula with higher bioavaila-bility and sustained action for treatment of erectile dysfunction. Expert Opin. Drug Deliv. 2014, 11, 1015-1022. [CrossRef]

46. Hosny, K.M.; Hassan, A.H. Intranasal in situ gel loaded with saquinavir mesylate nanosized microemulsion: Preparation, characterization, and in vivo evaluation. Int. J. Pharm. 2014, 475, 191-197.

47. Baboota, S.; Shakeel, F.; Ahuja, A.; Ali, J.; Shafiq, S. Design, development and evaluation of novel nanoemulsion formula-tions for transdermal potential of celecoxib. Acta Pharm. 2007, 57, 315-332. [CrossRef]

48. Aldawsari, H.M.; Hosny, K.M. Solid lipid nanoparticles of Vancomycin loaded with Ellagic acid as a tool for overcoming nephrotoxic side effects: Preparation, characterization, and nephrotoxicity evaluation. J. Drug Deliv. Sci. Technol. 2018, 45, 76-80. [CrossRef] 